\title{
Contributions of classical and molecular cytogenetic in meiotic analysis and pollen viability for plant breeding
}

\author{
M.P. Lavinscky, M.M. Souza, G.S. Silva and C.A.F. Melo \\ Departamento de Ciências Biológicas, Universidade Estadual de Santa Cruz, \\ Ilhéus, BA, Brasil \\ Corresponding author: M.M. Souza \\ E-mail: souzamagg@yahoo.com.br \\ Genet. Mol. Res. 16 (3): gmr16039582 \\ Received December 13, 2016 \\ Accepted August 11, 2017 \\ Published September 27, 2017 \\ DOI http://dx.doi.org/10.4238/gmr16039582 \\ Copyright (C) 2017 The Authors. This is an open-access article distributed under the terms of \\ the Creative Commons Attribution ShareAlike (CC BY-SA) 4.0 License.
}

\begin{abstract}
The analysis of meiotic behavior has been widely used in the study of plants as they provide relevant information about the viability of a species. Meiosis boasts a host of highly conserved events and changes in genes that control these events will give rise to irregularities that can alter the normal course of meiosis and may lead to complete sterility of the plant. The recombination of genes that occur in meiosis is an important event to generate variability and has been important in studies for genetic improvement and to create viable hybrids. The use of fluorescence in situ hybridization and genomic in situ hybridization (GISH) in meiosis allows the localization of specific regions, enables to differentiate genomes in a hybrid, permits to observe the pairing of homoeologous chromosomes, and if there was a recombination between the genomes of progenitor species. Furthermore, the GISH allows us to observe the close relationship between the species involved. This article aims to report over meiosis studies on plants and hybrids, the
\end{abstract}


use and importance of molecular cytogenetic in meiotic analysis and contributions of meiotic analysis in breeding programs.

Key words: Meiosis; GISH; FISH; Hybrids; Chromosome recombination; Plant breeding

\section{INTRODUCTION}

Chromosomes are vital structures in the organization and genomic structure of eukaryotic organisms. Their behavior in the reproduction controls the mechanisms of inheritance, and their organization regulates gene activity in the cell division process. In sexual reproduction, specific cells undergo meiosis and reduce to half their chromosomal set giving rise to genetically different daughter cells, restoring the diploid number of a body in gametic fertilization (Sumner, 2003). In meiosis, the main cellular events responsible for genetic variability is the crossing over, which together with the independent chromosome segregation provides the variability contained in a population, creating new allelic combinations, and thus giving rise to individuals with a different genotypic constitution of their parents. In meiosis, all steps are controlled by specific genes that operate in different processes to meiosis occurs regularly. On the other hand, gene mutations are the main causes of meiotic deficiencies. However, environmental and epigenetic factors may also influence the meiotic process (Sumner, 2003).

Studies in different stages of meiosis provide detailed information about the chromosome behavior and fertility of a species, providing information to help in crossing inter- and intraspecific hybridization in plant-breeding programs (Kiihl et al., 2011). The pairing between chromosomes, the genetic recombination, the degree of meiotic irregularities, and viability of gametes are information acquired through the meiotic analysis, and which are important for planning hybridizations through generations (Souza et al., 2003). An essential event in meiosis is the chromosome pairing, both for the occurrence of recombination and for the correct chromosome segregation (Fachinetto and Tedesco, 2009). When an error occurs in the chromosome pairing, the maintenance of bivalent or in the formation of the spindle fibers, the segregation can happen in an unbalanced way and gametes can receive an unbalanced number of chromosomes, leading to decrease of viable gametes (Souza et al., 2003).

Meiotic instability caused by irregularities can affect the fertility of the plant and can lead to the decadence of a plant variety of great importance to carry out continuous cytological analysis in breeding programs (Pagliarini, 2001). The stages of pre- and post-meiosis are controlled by a relatively small number of genes. The normal meiotic behavior demonstrates the degree of fertility of the plants, although the genes that control this process may have mutations that lead to irregularities and affect the fertility of an individual (Pagliarini, 2000).

In hybrids, meiosis consists of a key process that determines the fertility (Pagliarini, 2001). A hybrid will only be fertile or will only have some degree of fertility when presenting a regular meiosis and consequently the production of viable gametes. The presence of chromosomal irregularities during meiosis can significantly affect the genetic stability, meiotic index (MI) and pollen viability in hybrids. In that way, the study of meiosis in hybrids can speed up a breeding program because it provides information on fertility, and thus be more successful in the later stages to crossings (Pagliarini, 2001).

Techniques involving molecular cytogenetic have been widely used and have been an

Genetics and Molecular Research 16 (3): gmr16039582 
excellent methodology for the study of meiotic behavior. The fluorescence in situ hybridization (FISH) and genomic in situ hybridization (GISH) have been used to identify specific chromosomal regions, such as the genes $45 \mathrm{~S}$ and $5 \mathrm{~S}$ rDNA, single copy genes, centromeric and telomeric regions, through the application of FISH and identifying genomes of progenitors in interspecific hybrids by the GISH technique, being generally used in paternity confirmation in interspecific crosses (Silva and Souza, 2013). Moreover, when the GISH is applied in meiosis allows to observe how the chromosome pairing is occurring (homologous and homeologous), allowing to observe the meiotic behavior of hybrids, such as the formation of univalents, bivalents, and multivalents, as well as observe the occurrence of pairing between homeologous chromosomes, recombination frequency and position of chiasmata, and thus provides relevant information on steps that are crucial to the viability of a hybrid, once the successful pairing among homeologous chromosomes can determine the continuity of a breeding program (Silva and Souza, 2013; Melo et al., 2015).

This article aims to report over meiosis studies on plants and hybrids, the use and importance of molecular cytogenetic in meiotic analysis and contributions of meiotic analysis in breeding programs.

\section{Meiotic behavior}

In sexually reproducing organisms, cells that are present in the female and male sexual organs suffer two consecutive divisions, one reductional and other equational, halving their chromosomal content (Sumner, 2003). This process is called meiosis, forming genetically distinct bodies of genitors thanks to meiotic recombination. This entire process requires a precise chromosomal replication, which occurs in the synthesis phase (S phase) and it is ensured by checkpoints, which guarantee that the subsequent events of the cell cycle occur correctly (Sumner, 2003). During the cell cycle, the chromosome segregation should also be accurate to ensure cycle stability. The checkpoint of the spindle fibers regulates the segregation by detecting the chromosomes that are not connected to the spindle microtubules; the voltage loss of chromosomes that are aligned on the metaphase plate impedes cell cycle progression at anaphase, keeping the chromosomes in metaphase until all kinetochores are captured by spindle fibers (Gorbsky, 2015).

Meiosis is an event controlled by genes and high evolutionary stability; however, mutations in the genes responsible for meiotic control may result in abnormalities, directly affecting the fertility of the organism (Karsburg and Battistin, 2006). In plants, the microsporogenesis haploid microspore results in four, while the gynosporogenesis results in a haploid gynosporo (Singh, 2003).

In the first meiotic division occurs segregation of homologous chromosomes (reduction division) and in the second division is the segregation of sister chromatids (equational division) and each daughter cell carries half the parents' genetic material (Zamariola et al., 2014). The formation of a synaptonemal complex, allowing the pairing between homologous chromosomes and meiotic recombination, is characteristic of prophase I of meiosis and is a prerequisite for the reduction division (Bass et al., 2003).

In metaphase I, homologous chromosomes already in repulsion since the end of prophase I are only connected by the chiasmata. All these meiotic events are also precisely controlled by checkpoints and, in some meiotic mutants, mainly the synaptic points are ignored (Singh, 2003). When the kinetochore in at least one chromosome is not captured by

Genetics and Molecular Research 16 (3): gmr16039582 
the spindle fibers in metaphase I or II, or when the chromosomes are not all aligned on the metaphase plate, proteins that regulate the cycle indicate to pause cell division, and this delay provides time for the cells to correct the error and ensure the perfect chromosome segregation (Yamamoto et al., 2008).

\section{Meiosis study associated with plant breeding}

The study of the meiotic behavior of the plants and the observation of irregularities in meiosis can affect the fertility of an individual and interfere with plant improvement programs (Pagliarini, 2001). The genetic diversity of plant species has been explored, and this variation can increase agricultural productivity and produce more economically viable crops (Harrison et al., 2010). To increase this diversity and efficiency of cultures is important to understand the mechanism that creates variability and how that variation is generated and transmitted (Harrison et al., 2010). Meiosis represents a series of highly conserved and coordinated events, and cytological and molecular studies have been conducted in different organizations to understand how the genetic material is passed from generation to generation (Boateng et al., 2008). Research with plant breeding started around the twentieth century and played an important role in increasing productivity and improving characteristics of species of agronomic interest (Pagliarini, 2001). The study of meiosis in plants has been relevant for breeding, whereas in meiosis occurs recombination of genes (Fachinetto and Tedesco, 2009). Understanding fertility of selected species for breeding programs and intra- or interspecific hybridization increases the chances of successful crosses (Martins et al., 2010).

Interspecific hybridizations are performed in breeding programs, often for introgression of resistance genes. In three wild species of Caricaceae family, Vasconcellea goudotiana, Vasconcellea quercifolia, and Jacaratia spinosa, which are very promising for papaya improvement programs due to the resistance to disease and cold, meiosis was partially typical, presenting pollen viability with satisfactory values ranging from $68 \%$ in $V$. goudotiana to $96 \%$ in $J$. spinosa (Silva et al., 2012). This study suggests that in breeding programs involving hybridization, the wild species $V$. goudotiana can be used as a maternal parent, as this species had the lowest MI and lower pollen viability, compared to the other studied species (Silva et al., 2012).

Meiotic studies have relevance in the species selection for interspecific hybridization as an alternative to introgression of resistance genes from wild species cultivars. Three species of Passiflora were analyzed for meiotic behavior, P. setacea, P. incarnata, and $P$. edulis f. flavicarpa, the latter being a species of high economic importance; however, it is very susceptible to diseases. The study of meiotic behavior showed regular chromosome pairing in the three studied Passiflora species, which confirmed the presence of nine bivalent and therefore the phases of meiosis were regular with little abnormalities and formation of viable pollen grains, which may favor the use of these species in interspecific hybridizations (SoaresScott et al., 2003). The meiotic behavior of $P$. edulis f. flavicarpa genotypes identified as self-compatible, with pure white flowers, was regular with MI of $96.3 \%$, compared to selfincompatible genotype with MI of $97.7 \%$, indicating promising self-compatible genotypes for use in breeding programs of yellow passion flower (Souza et al., 2010).

The variation in chromosome number, when not known, makes difficult the breeding through hybridization. Studies of chromosome number and meiotic behavior were conducted to identify and explain the high rates of gametes in unviable access and Brachiaria brizantha (Gramineae) hybrids. The analysis carried out in 22 accessions of this species revealed

Genetics and Molecular Research 16 (3): gmr16039582 
the existence of 18 tetraploids, one diploid, and three hexaploids. Highly irregular meiotic behavior was identified in hexaploid and tetraploid, with high levels of viable pollen grains suggesting that these accesses are not used as parents in breeding programs (Mendes-Bonato et al., 2002).

Meiotic behavior evaluation of various plant species allowed the identification of abnormalities that affect fertility, and some mutations that can be successfully exploited by breeding programs, mainly by the total male sterility (Pagliarini, 2000). In the male sterile, the pollen grain is impractical and cannot germinate or produce seeds to impregnate, wherein the female reproductive system is not changed. In triticale meiotic instability due to the occurrence of laggard chromosomes, micronucleus formation in tetrads, irregular segregation, and unviable pollen grains lead to the occurrence of male sterility (Guerra, 2008). This condition can be quite exploited in breeding programs with the aim of producing hybrid seeds because it prevents inbreeding; however, these individuals should be carefully selected because of several meiotic irregularities (Guerra, 2008).

The meiotic analysis may be important to select strains that present meiotic stability and have high levels of viable pollen grains to contribute to the planning of breeding programs. Twelve strains of Capsicum L. were studied as the meiotic behavior and pollen viability to identify which of these materials could be used in breeding programs. Meiosis analysis showed normal behavior in most strains during the phases of meiosis and a high percentage of pollen viability, but three lines, CNPH 0283, CNPH 3000, and CNPH 3773, had a lower percentage of viable pollen grains with 77, 66, and 58\%, respectively (Pozzobon et al., 2011). These results indicate the importance of cytological studies to assist in the selection of genotypes that present meiotic stability and are potentially fertile.

Genomes are considered unstable as the meiotic behavior may be the result of evolutionary changes in some species. The observation of meiotic behavior in diploid species of Solanum, S. macrocarpon, S. aethiopicum, S. gilo, S. anguivi, and S. melongena showed unstable genomes with a high incidence of chromosomal bridges and uneven anaphase, leading to the formation of unviable pollen grains. The meiotic behavior analysis of these species indicated the need for careful selection in using them as progenitors in breeding programs because of meiotic instability and low pollen viability, which can cause infertility in plants (Oyelana and Nwangburuka, 2013).

Studies with Arabidopsis and autotetraploid revealed that the meiotic recombination rates were significantly higher in tetraploid with a multivalent formation when compared with diploid (Pecinka et al., 2011). These analyses showed that the evolutionary success of polyploid plants in nature could be related to the increase in chromosomal recombination, thereby increasing the genetic diversity and the potential for adaptation to more severe natural environments. Furthermore, the duplicated genome of polyploid can help stabilize the chromosome together with segregation in normal anaphase and improve bivalent formation in allotetraploids, increasing the genetic diversity and contributing to the improvement of plants (Pecinka et al., 2011).

\section{Meiotic x fertility irregularities in plants}

Meiotic instability is strongly associated with fertility of a species in plants, and it is of great importance to the continuous cytological analysis in breeding programs (Pagliarini, 2001). The meiotic instability may lead to the formation of aneuploidy plants, involving the

Genetics and Molecular Research 16 (3): gmr16039582 
loss or gain of one or a few chromosomes and arise from gametes with a variable number of chromosomes caused by irregular segregation, failures in the synapse or delays in chromatid migration to the poles at anaphase I or II. These plants may have reduced fertility or be completely infertile (Pagliarini, 2001).

The formation of unreduced gametes or $2 \mathrm{n}$ gametes may arise from errors in meiosis $\mathrm{I}$, in which the chromosomes do not migrate to the poles in the anaphase and form a cell with a diploid number or when there is a failure in cytokinesis in meiosis II, forming dyads or triads. This phenomenon can occur spontaneously in almost all plants or may increase with interspecific crosses and environmental factors (Schifino-Wittmann and Dall'Agnol, 2001). Unreduced gametes were observed in some species of Brassica at low frequencies; however, in interspecific hybrids, the frequency was higher. It was reported that an interspecific hybrid $(\mathrm{CnCcAB})$ of the crossing B. napus (AACnCn) vs B. carinata $(\mathrm{BBCcCc})$ yielded a high proportion of gametes with approximately the same chromosomal complement and that such failure arose by chromosomal segregation during the first meiotic division and by low temperatures, which may have also interfered with the stages of meiosis. These unreduced gametes are viable and can be used in breeding programs to induce polyploidy (Mason et al., 2011).

The polyploidy may be a way to combine genes from different species, having an important role in the evolutionary process in some species and a valuable tool for plant breeding. However, a small degree of relatedness of species for which there is a homology among the chromosomes is required, resulting in the formation of divalent or multivalent and chromosomal recombination among different species involved in hybridization (Pagliarini, 2001).

In plants, polyploidy multiplication of the entire chromosome complement may cause problems in meiosis and the maintenance of the polyploid state over generations requires special mechanisms to control the correct pairing and chromosome segregation of more than two counterparts. However, high recombination rates in polyploid plants can lead to a rapid process of diversification and optimize the domestication of wild species in different environments (Pecinka et al., 2011). Polyploid plants can be generated through polyploidy events by somatic duplication or unreduced gametes and are considered an evolution in the plant genome (Zamariola et al., 2014).

In 22 Brachiaria brizantha accessions, several irregularities were found as the formation of multivalent related to polyploidy, early chromosomes and stragglers, irregular segregation, micronucleus formation and polyads, especially in polyploid. These irregularities may compromise the viability of gametes and affect the fertility of the plant (Mendes-Bonato et al., 2002).

One of the responsible factors for the success of breeding is the selection of genotypes with a high percentage of viable gametes (Techio et al., 2006). Pollen viability is considered a valuable tool for assessing the fertility of the male gamete and can be determined by using different methods and different dyes, such as acetic carmine, Alexander's solution, fluorescein diacetate, and Lugol reagent. These methods use chemical dyes that react with cellular components of the mature pollen grain, indicating whether the pollen is viable or unviable (Souza et al., 2004).

The cytogenetic study in meiosis and estimated pollen grain fertility was made in Citrus hybrids [Citrus clementine vs (C. paradisi vs C. tangerine)]. The meiotic behavior was regular in most of the analyzed plants, with MI around $90 \%$ and pollen viability above $80 \%$, but six plants were observed presenting viability below $70 \%$ due to some irregularities in the phases of meiosis, as univalent, laggard chromosomes and bridges in anaphase. However, these irregularities do not affect the fertility of the plant and these hybrids had the ability to produce viable gametes and can be used as pollen donors (Cavalcante et al., 2000).

Genetics and Molecular Research 16 (3): gmr16039582 
Analysis of meiotic behavior and pollen viability in four Capsicum accessions showed regular meiosis in most analyzed cells, presenting few irregularities as the early migration of chromosomes, laggard chromosomes, and asynchrony. In Capsicum, despite the irregularities, the pollen viability ranged from 96.53 to $98.91 \%$, and the irregularities did not affect the fertility of the species (Martins et al., 2010). The pollen viability in most species of Passiflora has been more than $80 \%$ (Souza et al., 2003, 2004). Studies performed in 17 Passiflora species, wild and domesticated, showed high levels of pollen viability above $90 \%$, except in P. pentagona that obtained $78 \%$ viability (Souza et al., 2004). The pollen viability of $P$. edulis, $P$. incarnata, $P$. setacea and two hybrids were observed for 2 years. In $P$. incarnata the pollen viability ranged from $55 \%$ in the first year to $85.3 \%$ in the second year, with an average of $70.2 \%$ of viable pollen grains; in $P$. edulis the average was $94.3 \%$, and in $P$. setacea the average was $81.2 \%$; when it comes to interspecific hybrids in Passiflora, the average pollen viability in the somatic hybrid was $37.2 \%$, and in the sexed hybrid it was $65.76 \%$ (Soares-Scott et al., 2003).

Through analysis by Alexander solution, the unviable pollen grains (GP) can be considered of three types: empty (T1 - no cytoplasm), contracted (T2 - contracted cytoplasm), and sprayed (T3 - sprayed cytoplasm) (Souza et al., 2004). The GP T1 is characterized by smaller size than achievable in most Passiflora species, and the absence of cytoplasm observed by the green staining with Alexander solution was only the wall that reacts with the dye. In the T2 GP both the wall and the cytoplasm react to the staining; however, it is observed a space between the cell wall and cell membrane and a cytoplasmic shrinkage (Souza et al., 2003). The GP T3 is little observed in species of Passiflora and is characterized by staining both the wall and the cytoplasm; however, the cytoplasm is observed in a fragmented way, with gaps in color with a lighter shade, and its size is compared to the GP T2. They are also found in giant-type pollen grains (considered viable and diploid) and micropolen resulting from unreduced gametes or chromosomal imbalance (Souza et al., 2004). In P. edmundoi, the pollen viability was $97.9 \%$, and the non-viable pollen grains were measured. It was observed a higher percentage of voids and contracted viable pollen grains relative to pollen grain suggesting that meiotic irregularities may have been the cause of pollen unfeasibility (Souza et al., 2003). Biotic and abiotic factors can interfere with the fertilization process in species that are not in their natural habitat (Souza et al., 2004) and mutations that occur during meiosis and post-meiosis can affect and reduce pollen viability of a species.

\section{Mutations in genes related to meiosis}

Mutations can spontaneously occur of spontaneous origin in natural populations induced by mutagens or as a result of interspecific hybridizations (Singh, 2003). Meiotic mutations can occur during DNA synthesis leading to pre-meiotic mutants, during prophase I causing synaptic mutants in anaphase I up to telophase II, causing disjunction mutants; postmeiotic mutations occur at the end of the second division, resulting in post-meiotic mutants, although the meiotic mutants are the most common in plants (Singh, 2003).

Meiotic mutations are identified by cytological observations, genetic evidence and quantity of eggs and aborted pollen (Singh, 2003). Synaptic mutants affect the formation of a synaptonemal complex in sub-phases of prophase and metaphase I (Golubovskaya et al., 2011). These mutants can be assynaptics (e.g., asyl), that cause synapses and affect the pairing of homologous chromosomes or desynaptic1 (e.g., $d s y 1, d s y 10$ ) that cause desynapsis and undo the pairing between chromosomes precociously. In both cases, there will be the formation of univalents rather than divalent in prophase I (Liu and Qu, 2008).

Genetics and Molecular Research 16 (3): gmr16039582 
Cytological studies have been conducted to identify several important mutants as "ameiotic 1" (am 1$)$, which are necessary to establish the meiotic cell cycle in maize, and "absence of first division" (afdl) necessary to occur the segregation of homologous chromosomes and the halving of the chromosome set. Usually, these mutants are identified in segregating generations and are distinguishable from normal plants by the amount of pollen and aborted ovules. Synaptic mutants are the most frequent in the literature, and from the fifteen disynaptic genes found, thirteen are from the spontaneous origin and two of X-ray radiationinduced (Singh, 2003). The consequences are the formation of unbalanced androspore and gymnosperms resulting in reduced pollen viability (Singh, 2003).

Many meiotic mutations have been identified in Arabidopsis, as in SYN1/DIF1 genes that cause errors in chromosome pairing and lead to the formation of univalent with segregation at irregular anaphase I and II; resulting in post-meiotic products of irregular sizes and shapes, variable ploidy and formation of unbalanced and unviable gametes (Liu and Qu, 2008).

For the pairing occurrence, recombination and crossing over among homologous chromosomes are required so that there is a break in the double-stranded DNA (DSBs - double strand break), which, in most species, is catalyzed by the Spo11 protein, highly conserved among species (Edlinger and Schlögelhofer, 2011). Studies in Arabidopsis thaliana showed that mutations in the Spo11 protein drastically reduce the formation of chiasmata and is associated with the absence of synapse in prophase I. These mutations may affect the entire course of meiosis since the decrease of genetic variability to total infertility of the plant (De Muyt et al., 2009). Mutations in the ASY1 gene result in assinapse and reduce the formation of chiasmata that holds homologous chromosomes up to anaphase I, forming univalents. Other studies show that the formation of DSB can be normal in asyl mutants; however, recombination levels decrease due to the low frequency of chiasmata (Sanchez-Moran et al., 2007).

In Zea mays L., maize mother cells of pollen grain were analyzed by molecular cytogenetics using FISH to identify disynaptic meiotic mutants (Bass et al., 2003). Mutants $d y$ and $d s y l$ were identified by changing the organization of telomere-shaped bouquet in prophase I. The mutant $d s y 1$ affects the formation of the synapse among homologous and the mutant $d y$ reduces recombination rates. Some telomeres were located in the center of the core preventing telomere interaction/nuclear membrane, the recognition of homologous and chromosome pairing, thus found many univalent chromosomes in the following stages of prophase I with the formation of unbalanced pollen grains and reduction of plant fertility (Bass et al., 2003).

Studies on the meiotic mutants contribute to understanding the regulatory mechanisms of meiotic cells and DNA repair that occur in eukaryotes. In maize more than 60 mutants were identified, representing about 35 genes and the majority of these mutants are related to errors in the formation of bivalent defects, homologous pairing, synapse adjustment, and recombination, resulting in unviable gametes at the end of meiosis (Golubovskaya et al., 2011).

\section{Study of meiotic behavior in hybrid}

In breeding programs, the interspecific crosses are valuable tools to generate variability in crop plants (Pagliarini, 2001), while meiotic analysis associated with improvement reduces the time needed for producing new hybrid cultivars, once hybrids with meiotic irregularities and/or unviable pollen grains can be discarded, and thus allow selection of more stable genotypes (Pozzobon et al., 2011). Usually hybrids derived from crosses among species with similar genomes tend to have high matching rate among homoeologous chromosomes,

Genetics and Molecular Research 16 (3): gmr16039582 
whereas in species that are genetically distant, the pairing among homologous chromosomes does not occur or occur at a very low level and hybrid cannot go through regular meiosis and have some degree of fertility (Lee et al., 2011). Thus, the genetic distance can be a limiting factor in breeding. In hybrids of Paphiopedilum delenatti vs P. callosum and P. delenatii vs P. glaucophyllum many meiotic irregularities and low levels of chromosome pairing were observed, which reflects the genetic distance among the progenitor species (Lee et al., 2011).

The use of data on chromosome pairing is useful in the genotype selection since the degree of homology among the hybrid homoeologous chromosomes demonstrates the degree of relationship between the parents (Techio et al., 2006). The chromosome pairing of two tetraploid species Arachis glabrata and A. nitida $(2 n=4 x=40)$ produced different configurations in diakinesis and metaphase I. In A. glabrata 21 different settings were found since the 20II formation until the 4II + 8IV formation and in $A$. nitida, seven settings, from $20 \mathrm{II}$ to $2 \mathrm{I}+12 \mathrm{II}+2 \mathrm{III}+2 \mathrm{IV}$. The $8 \mathrm{IV}$ association observed in $A$. glabrata may be an indication that this species arose from an autopolyploid (Ortiz et al., 2011). The occurrence of bivalent and multivalent is considered as indicative of meiotic recombination, and the success of hybridization depends on the recombination efficiency. Many wild species carry interesting features to be exploited in breeding programs, and the ability to produce interspecific hybrids is very relevant. The observation of meiotic behavior and pollen viability of wild species can provide important information about the genome, recombination rate, fault degree and viability of gametes so that crossings are successful in using these species in interspecific hybridization programs (Souza et al., 2003).

The analysis of chromosome behavior in meiosis can also contribute with studies and phylogenetic similarity among genomes from different species, and thus estimate the frequency of recombination that may occur in interspecific hybrids (Techio et al., 2006). Brassica interspecific hybrids have been produced to identify the relationship among the genomes of three species: $B$. rapa $(2 n=20, \mathrm{AA}), B$. nigra $(2 n=16, \mathrm{BB})$, and B. oleracea $(2 n$ $=18, \mathrm{CC})$ through pairing chromosome analysis in meiosis. Three allotetraploid individuals of Brassica were produced: B. juncea $(2 n=4 x=36$, AABB $), B$. napus $(2 n=4 x=38$, AACC), and $B$. carinata $(2 n=4 x=34, \mathrm{BBCC})$ derived from crosses among diploid species; the study of the behavior of these hybrids showed that the genomes A and $\mathrm{C}$ most recently differed by a great distance from a common ancestor and B genome (Mason et al., 2011). In Paphiopedilum, chromosomal behavior at metaphase I of eight hybrids was analyzed to identify homology in the genome of the progenitor's species and provide useful information in the creation of this species breeding programs. The chromosome pairing in hybrids of $P$. delenatti $v s$ crossing $P$. bellatulum $(2 n=26)$ had an average of 6.9 univalents and 10.7 bivalents per meiocyte; in $P$. delanatii hybrids vs P. micranthum $(2 n=26) 3.1$ univalents and 11.6 bivalents were found, suggesting greater homology between the genomes of these two last species (Lee et al., 2011).

In hybrid triploids $(2 n=3 x=21)$ resulting from the crossing of elephant grass (Pennisetum purpureum, $2 n=4 x=28$ ) with millet (Pennisetum glaucum, $2 n=2 x=14$ ), several chromosomal alterations were observed such as formation of univalents and multivalents, early rise of chromosomes in the first and second meiotic division, irregular segregation, bridges in anaphase, adherent chromosomes, asynchrony, cells forming with unequal sizes, cytomixis, abnormal spindle, binucleate cells, and formation of micronuclei (Techio et al., 2006). These changes were due to the hybrid triploid nature where the pairing and chromosome segregation are always irregular and lead to the complete sterility of the plant.

In a somatic hybrid $(4 n=4 x=36)$ obtained from crossing Passiflora edulis f. flavicarpa

Genetics and Molecular Research 16 (3): gmr16039582 
vs P. cincinnata $(2 n=18)$ the formation of 18 bivalents was observed in most cells, revealing a stable meiosis (Barbosa et al., 2007). The study of meiotic sexual behavior in a sexual hybrid (P. edulis f. Flavicarpa vs P. setacea, $2 n=18$ ) and a somatic hybrid ( $P$. edulis f. Flavicarpa vs $P$. incarnata, $2 n=36$ ) showed the formation of bivalents and multivalent in metaphase I and the presence of some abnormalities in the different stages of meiosis; these hybrids produced viable pollen grains and can be used in the improvement of passion fruit (Soares-Scott et al., 2003).

The crossing between species with different chromosome numbers can be difficult, since the chromosome number is a limiting factor for the occurrence of a regular meiosis with all chromosomes paired in meiosis I. The interspecific cross between Passiflora sublanceolata $(2 n=22)$ vs $P$. cincinnata $(2 n=18)$ was probably unsuccessful due to the fact that they possess different chromosome number (Conceição et al., 2011).

\section{Molecular cytogenetic (FISH) and studies on meiosis in plants}

The FISH extends the power of resolution to the chromatin display, providing essential information for the study of chromosome behavior in meiosis, data that cannot be obtained by classical cytogenetic application techniques (Dang et al., 2015). In the meiotic analysis, the observation of numerical chromosomal changes such as nullisomics (Ji et al., 1997) and genome structure (Scholes, 2011) has been facilitated by the identification of homologous chromosomes using rDNA probes, genomic regions commonly found and used in the comparative meiotic analysis. The location of particular regions by FISH for repetitive sequences, like telomeric, and for satellite DNA or for sequences with a few copies brought benefits for understanding the meiotic behavior of various organisms whose essential cytological events in meiosis, as the recognition and matching among homologous chromosomes (crossing over), chromosome disjunction, and formation of recombinant complexes, are the main target elements in cytogenetic analysis before and during the meiotic cycle (Schwarzacher, 2003).

The chromosome pairing before leptotene has been an important subject of study, suggesting mechanisms acting on the recognition of homologous chromosomes and chromosomal regions where multiple sequences are involved in this process. Such regions can be located and characterized through the use of FISH by allowing the definition of the recognition pattern of chromosomes in meiosis. The telomere, which in plants generally has the monomer sequence TTTAGGG, has the important role of recognition and pairing of homologous chromosomes, even before the leptotene being the first chromosome region to form synapse while the interstitial regions are not yet matched, and being such essential recognition for the progression of the meiotic process (Bozza and Pawlowski, 2008). Additionally, the lack of homology in distal regions of chromosome arms causes the wrong pairing between homologous in meiosis. The telomeric region operates in chromosomal organization and formation of chromosomal domains in the interphase nuclei and pre-meiotic often connected to the nuclear membrane. As telomeric regions, subtelomeric regions are also essentials for the recognition and pairing of homologous chromosomes at the beginning of meiosis and in some cases even before the leptotene (Schwarzacher, 2003). In potato (Solanum tuberosum L.) two subtelomeric regions were identified and then located by FISH, revealing chromosomes with preferred regions in chromosome short and long arms as well as the colocalization of two different sequences in the same subtelomeric region. This suggests the role of these chromosomal regions in nuclear domains for the correct recognition and pairing between homologous chromosomes in meiosis (Torres et al., 2011).

Genetics and Molecular Research 16 (3): gmr16039582 
Meiotic chromosomes can be greater than the mitotic chromosomes in the sense of the information obtained via the application of FISH technique using probes for few copies or of a single copy. Pachytene chromosomes have been used for the location of sequences via FISH that are not displayed in metaphase chromosomes allowing visualization of chromosomal initial pairing in meiosis in relation to the distribution of cytological markers for physical mapping (Han et al., 2009), mainly for preparing pachytene maps using bacterial artificial chromosome (BAC) clones (Kulikova et al., 2001).

The location of contigs in BACshave been used in BAC FISH for chromosome painting, recombination view and pairing at meiosis, and promising technique for analysis the synteny and of collinearity between chromosomal markers (Han et al. 2009). As BACs, other genomic vectors are also widely used in FISH cells in meiosis I. Fosmids with genomic insert to the sixth chromosome pair of Cucumis sativus L. was used for heterologous hybridization in pachytene chromosomes of $C$. melo L., where hybridization in the first chromosome pair showed centromeric and neocentromeric repositionings as major evolutionary events acting in speciation of phylogenetically close taxa (Han et al., 2009).

The in situ location of single copy sequences or small repetitive regions, such as simple sequence repeats (SSR), is difficult in later levels of chromosome compaction and was observed in meiotic chromosomes whose compression in prophase I favored the location of smaller sequences (Schwarzacher, 2003). The location of SSR regions in chromosomes and the development of physical maps revealed the existence of variability in SSRs located in situ in Brassica rapa ssp chinensis morphotypes, whose centromeric and pericentromeric distribution can be attributed to meiotic stability and other events related to cell cycle (Zheng et al., 2016). The karyotype analysis by location of rDNA 45S sites in chromosomal mitotic showed chromosomal translocations among genomes in a hybrid of allopolyploid oat species (Avena), suggesting that this characteristic is the main cause of meiotic incongruity in the analyzed allopolyploid (Nikoloudakisa and Katsiotisa, 2015).

\section{Use of GISH for meiotic analysis in hybrids}

GISH consists of an FISH modification, in which the total genome of a species is labeled and used as a probe to identify the genomic interspecific hybrids (Schwarzacher, 2003). The meiotic analysis of hybrids based on GISH have been conducted for viewing the matching among homoeologous chromosomes, especially the rate of chiasmata and thus recombination among homoeologous chromosomes, since recombination allows genes that are introgressed in species of agronomic interest and promotes chromosome pairing at metaphase, resulting in the normal segregation during anaphase of meiosis I.

Using GISH, it was possible to distinguish the genomes of two closely related species, Lycopersicon esculetum and L. peruvianum (both $2 n=2 x=24$ ), currently belonging to the Solanum genus, and so check the match among the homoeologous chromosomes and the presence of recombinations (Parokonny et al., 1997). The $\mathrm{RC}_{1}, \mathrm{RC}_{2}$ and $\mathrm{RC}_{3}$ progenies involving somatic hybrids (L. esculetum vs L. peruvianum) were analyzed, being possible to observe a regular pairing and a high degree of recombination between homoeologous chromosomes in the $\mathrm{RC}_{1}$ progeny. In $\mathrm{RC}_{2}$ and $\mathrm{RC}_{3}$, the homoeologous continued to be chromosome pairs (in the absence of homologous) and chiasmata were found exclusively in the distal segments of chromosomes (Parokonny et al., 1997). The chromosome pairing in meiosis was studied in lines of cultivated tomato, L. esculetum, which contained one or two chromosomal segments

Genetics and Molecular Research 16 (3): gmr16039582 
of wild Solanum lycopersicoides species. The average chiasma frequency of chromosome seven, containing introgression terminal at the long arm was estimated at 0.78 . In two long lines, which had introgressed segments, the frequency of chiasmata was greatly reduced when compared with strains with a single introgression. The frequency of cells with univalent was also much greater in those strains with two introgressions, indicating chromosome pairing failure (Ji and Chetelat, 2007).

GISH was used to verify the formation of bivalents between two species of different types, Festuca and Lolium. A hybrid $\mathrm{F}_{1}(n=4 x=28)$ was obtained from $F$. arundinacea var. cross with tetraploid glaucescens (GGG'G') vs L. multiflorum artificial tetraploid (LmLmLmLm). This $\mathrm{F}_{1}$ hybrid was back-crossed to diploid L. multiflorum, producing an $\mathrm{RC}_{1}$ triploid progeny $(2 n=3 x=21, \mathrm{LmLmG})$ (Morgan et al., 2001). The GISH revealed that at metaphase I of individuals $\mathrm{RC}_{1}$ meiosis there is a predominance of bivalents formed by homologous chromosomes $(\mathrm{LmLm})$, univalents $(\mathrm{G})$, and the presence of some trivalents formed by two homologous ( $\mathrm{LmLm}$ ) and one homoeologous $(\mathrm{G})$, with the presence of two chiasmata per chromosome. Although only occurs the formation of some trivalents, it was possible to occur the recombination among the genomes, in which the features of interest of the genome $\mathrm{G}$ were introduced in the genome Lm (Morgan et al., 2001).

In $\mathrm{F}_{1}$ hybrid and $\mathrm{RC}_{1}$ and $\mathrm{RC}_{2}$ plants involving a cross between Lilium longiflorum (LL) vs L. rubellum (RR), the GISH was used to verify whether recombinations between homoeologous chromosomes occurred. $F_{1}$ plants (LR) were only observed in the presence of a chiasma among homoeologous chromosomes, but when these hybrids were transformed into amphidiploid (LLRR), pairing occurred only among homologous chromosomes without any recombination among the genomes. The RC1 and RC2 individuals had no recombinant chromosomes, indicating the absence of linkage among homoeologous chromosomes (Lim et al., 2000).

Detailed analysis of metaphase I in six hybrids of Festuca pratensis vs Lolium perenne $(2 n=4 x=28)$ found that the chromosomal average settings in all hybrids were: 1.13 univalents, 11.51 bivalents, 0.32 trivalents, and 0.72 quadrivalents. The frequency was 21.96 chiasmata per cell. GISH showed that the pairing was predominantly intragenomic (Zwierzykowski et al., 2008).

The chromosome pairing at metaphase I analyzed in eight hybrids involving Paphiopedilum species of the genus using GISH showed the phylogenetic relationship among the progenitor's species. The inability to discriminate parental chromosomes with GISH technique in $P$. delenatii hybrids vs $P$. micranthum may have been due to the short distance between the genomes of the parents of these hybrids (Lee et al., 2011). In hybrids involving Brassica maurorum $(2 n=16, \mathrm{MM})$ vs B. rapa $(2 n=20$, AA) all chromosomes remained without pairing in $28 \%$ of mother cells of the pollen grain, suggesting a relatively low homology between the genomes M and A (Yao et al., 2010).

In metaphase I of meiosis in interspecific hybrids of Musa acuminata (AA) vs $M$. balbisiana (BB), via GISH, the presence of univalents, bivalents, trivalents, and multivalents involving homoeologous chromosomes and the presence of recombinant chromosomes between the genomes A and B were observed. The presence of recombinant chromosomes in Musa hybrids, as well as in other plant species, is important for the domestication and breeding cultivars (Jeridi et al., 2011).

\section{ACKNOWLEDGMENTS}

We hank FAPESB (Fundação de Amparo à Pesquisa do Estado da Bahia) and CAPES

Genetics and Molecular Research 16 (3): gmr16039582 
(Coordenação de Aperfeiçoamento de Pessoal de Nível Superior) for the scholarships granted to the authors; CNPq (Conselho Nacional de Desenvolvimento Científico e Tecnológico) for the scholarship awarded to M.M. Souza.

\section{REFERENCES}

Barbosa LV, Mondin M, Oliveira CA, Souza AP, et al. (2007). Cytological behavior of the somatic hybrids Passiflora edulis f. flavicarpa + P.cincinnata. Plant Breed. 126: 323-328. https://doi.org/10.1111/j.1439-0523.2007.01362.x

Bass HW, Bordoli SJ and Foss EM (2003). The desynaptic (dy) and desynaptic1 (dsy1) mutations in maize (Zea mays L) cause distinct telomere-misplacement phenotypes during meiotic prophase. J. Exp. Bot. 54: 39-46. https://doi. org/10.1093/jxb/erg032

Boateng KA, Yang X, Dong F, Owen HA, et al. (2008). SWI1 is required for meiotic chromosome remodeling events. Mol. Plant 1: 620-633. https://doi.org/10.1093/mp/ssn030

Bozza CG and Pawlowski WP (2008). The cytogenetics of homologous chromosome pairing in meiosis in plants. Cytogenet. Genome Res. 120: 313-319. https://doi.org/10.1159/000121080

Cavalcante HC, Schifino-Wittmann MT and Dornelles ALC (2000). Meiotic behavior and pollen fertility in an openpollinated population of 'Lee' mandarin. Sci. Hortic. (Amsterdam) 86: 103-114. https://doi.org/10.1016/S0304$\underline{4238(00) 00139-4}$

Conceição LDHCS, Souza MM, Belo GO, Santos SF, et al. (2011). Hybridization among wild passionflower species. Rev. Bras. Bot. Braz. J. Bot. 34: 237-240. https://doi.org/10.1590/S0100-84042011000200011

Dang J, Zhao Q, Yang X, Chen Z, et al. (2015). A modified method for preparing meiotic chromosomes based on digesting pollen mother cells in suspension. Mol. Cytogenet. 8: 80. https://doi.org/10.1186/s13039-015-0184-x

Edlinger B and Schlögelhofer P (2011). Have a break: determinants of meiotic DNA double strand break (DSB) formation and processing in plants. J. Exp. Bot. 62: 1545-1563. https://doi.org/10.1093/jxb/erq421

Fachinetto JM and Tedesco SB (2009). Número cromossômico, análise meiótica e estimativa da viabilidade polínica em populações de Hyptis mutabilis (Rich.) Briq. Rev. Bras. Pl. Med. 11: 110-116. https://doi.org/10.1590/S1516$\underline{05722009000100017}$

Golubovskaya IN, Wang CJ, Timofejeva L and Cande WZ (2011). Maize meiotic mutants with improper or nonhomologous synapsis due to problems in pairing or synaptonemal complex formation. J. Exp. Bot. 62: 1533-1544. https://doi.org/10.1093/jxb/erq292

Gorbsky GJ (2015). The spindle checkpoint and chromosome segregation in meiosis. FEBS J. 282: 2471-2487. https:// doi.org/10.1111/febs.13166

Guerra D (2008). Caracterização fenotípica e citogenética da macho-esterilidade em triticale. Universidade Federal do Rio Grande do Sul, Porto Alegre. Available at [http://hdl.handle.net/10183/14307].

Han Y, Zhang Z, Liu C, Liu J, et al. (2009). Centromere repositioning in cucurbit species: implication of the genomic impact from centromere activation and inactivation. Proc. Natl. Acad. Sci. USA 106: 14937-14941. https://doi. org/10.1073/pnas.0904833106

Harrison CJ, Alvey E and Henderson IR (2010). Meiosis in flowering plants and other green organisms. J. Exp. Bot. 61: 2863-2875. https://doi.org/10.1093/jxb/erq191

Jeridi M, Bakry F, Escoute J, Fondi E, et al. (2011). Homoeologous chromosome pairing between the A and B genomes of Musa spp. revealed by genomic in situ hybridization. Ann. Bot. 108: 975-981. https://doi.org/10.1093/aob/mcr207

Ji Y and Chetelat RT (2007). GISH analysis of meiotic chromosome pairing in Solanum lycopersicoides introgression lines of cultivated tomato. Genome 50: 825-833. https://doi.org/10.1139/G07-069

Ji Y, Raska DA, McKnight TD, Islam-Faridi MN, et al. (1997). Use of meiotic FISH for identification of a new monosome in Gossypium hirsutum L. Genome 40: 34-40. https://doi.org/10.1139/g97-005

Karsburg IV and Battistin A (2006). Meiose e número cromossômico de cinco espécies da família Urticaceae do Rio Grande do sul. Rev. Ciênc. Agro-Ambientais 4: 47-60.

Kiihl PRP, Pereira ARA, Godoy SM, Stenzel NMC, et al. (2011). Chromosome stickiness during meiotic behavior analysis of Passiflora serrato-diditata L. (Passifloraceae). Cienc. Rural 41: 1018-1023. https://doi.org/10.1590/S0103$\underline{84782011005000076}$

Kulikova O, Gualtieri G, Geurts R, Kim DJ, et al. (2001). Integration of the FISH pachytene and genetic maps of Medicago truncatula. Plant J. 27: 49-58. https://doi.org/10.1046/j.1365-313x.2001.01057.x

Lee YI, Chang FC and Chung MC (2011). Chromosome pairing affinities in interspecific hybrids reflect phylogenetic distances among lady's slipper orchids (Paphiopedilum). Ann. Bot. 108: 113-121. https://doi.org/10.1093/aob/mcr114

Genetics and Molecular Research 16 (3): gmr16039582 
Lim KB, Chung JD, van Kronenburg BC, Ramanna MS, et al. (2000). Introgression of Lilium rubellum Baker chromosomes into L. longiflorum Thunb.: a genome painting study of the $\mathrm{F}_{1}$ hybrid, $\mathrm{BC}_{1}$ and $\mathrm{BC}_{2}$ progenies. Chromosome Res. 8: 119-125. https://doi.org/10.1023/A:1009290418889

Liu J and Qu LJ (2008). Meiotic and mitotic cell cycle mutants involved in gametophyte development in Arabidopsis. Mol. Plant 1: 564-574. https://doi.org/10.1093/mp/ssn033

Martins KC, Pereira TNS, Souza SAM and Costa FR (2010). Meiose e viabilidade polínica em acessos de Capsicum annuum e Capsicum baccatum. Cienc. Rural 40: 1746-1751. https://doi.org/10.1590/S0103-84782010000800012

Mason AS, Nelson MN, Castello MC, Yan G, et al. (2011). Genotypic effects on the frequency of homoeologous and homologous recombination in Brassica napus $\times$ B. carinata hybrids. Theor. Appl. Genet. 122: 543-553. https://doi. org $/ 10.1007 / \mathrm{s} 00122-010-1468-5$

Melo CAF, Silva GS and Souza MM (2015). Establishment of the genomic in situ hybridization (GISH) technique for analysis in interspecific hybrids of Passiflora. Genet. Mol. Res. 14: 2176-2188. https://doi.org/10.4238/2015. March.27.4

Mendes-Bonato AB, Valle CB, Pagliarini MS and Penteado MIO (2002). Caracterização citogenética de acessos de Brachiaria brizantha (Gramineae). Embrapa. Available at [http://ainfo.cnptia.embrapa.br/digital/bitstream/ item/104571/1/ Caracterizacao-citogenetica.pdf]

Morgan WG, King LP, Koch S, Harper JA, et al. (2001). Introgression of chromosomes of Festuca arundinacea var. glaucensses into Lolium multiflorum revealed by genomic in situ hybridization (GISH). Theor. Appl. Genet. 103: 696-701. https://doi.org/10.1007/s001220100634

De Muyt A, Pereira L, Vezon D, Chelysheva L, et al. (2009). A high throughput genetic screen identifies new early meiotic recombination functions in Arabidopsis thaliana. PLoS Genet. 5: e1000654. https://doi.org/10.1371/journal. pgen.1000654

Nikoloudakisa $\mathrm{N}$ and Katsiotisa A (2015). Comparative molecular and cytogenetic methods can clarify meiotic incongruities in Avena allopolyploid hybrids. Caryologia: Int. J. Cytol. Cytosyst. Cytogenet DOI: 10.1080/00087114.2015.1021170

Ortiz AM, Seijo JG, Fernandez A and Lavia GI (2011). Meiotic behavior and pollen viability Arachis glabrata and $A$. nitida species (Section Rhizomatosae, Leguminosae): implications concerning their polyploid nature and seed set production. Plant Syst. Evol. 292: 73-83. https://doi.org/10.1007/s00606-010-0397-8

Oyelana OA and Nwangburuka CC (2013). Correlation between meiotic behavior and species reproductive performance and ecological spread: a case study of eight Nigerian Solanum L. species. Int. J. Plant Breed. Genet. 7: 65-75. https:// doi.org/10.3923/ijpbg.2013.65.75

Pagliarini MS (2000). Meiotic behavior of economically important plant species: The relantion ship between fertility and male sterility. Genet. Mol. Biol. 23: 997-1002. https://doi.org/10.1590/S1415-47572000000400045

Pagliarini MS (2001). Citogenética aplicada ao melhoramento. In: Recursos Genéticos e Melhoramento - Plantas (Nass LL, Valois ACC, Melo IS, Valadares-Inglis MC, eds.). Fundação MT, Rondonópolis, 871-910.

Parokonny AS, Marshall JA, Bennett MD, Cocking EC, et al. (1997). Homoeologous paring and recombination in backcross derivatives of tomato somatic hybrids [Lycopersicon esculentum (+) L. peruvianum]. Theor Appl. Genet. 94: 713-723.

Pecinka A, Fang W, Rehmsmeier M, Levy AA, et al. (2011). Polyploidization increases meiotic recombination frequency in Arabidopsis. BMC Biol. 9: 24. https://doi.org/10.1186/1741-7007-9-24

Pozzobon MT, Souza KRR, Carvalho SIC and Reifschneider FJB (2011). Meiose e viabilidade polínica em linhagens avançadas de pimenta. Hortic. Bras. 29: 212-216. https://doi.org/10.1590/S0102-05362011000200013

Sanchez-Moran E, Santos JL, Jones GH and Franklin FC (2007). ASY1 mediates AtDMC1-dependent interhomolog recombination during meiosis in Arabidopsis. Genes Dev. 21: 2220-2233. https://doi.org/10.1101/gad.439007

Schifino-Wittmann MT and Dall'Agnol M (2001). Gametas não reduzidos no melhoramento de plantas. Cienc. Rural 31: 169-175. https://doi.org/10.1590/S0103-84782001000100028

Scholes D (2011). Plant Cytogenetics: Genome Structure and Chromosome Function. (Bass H and Birchler J, eds.). Springer, 462.

Schwarzacher T (2003). Meiosis, recombination and chromosomes: a review of gene isolation and fluorescent in situ hybridization data in plants. J. Exp. Bot. 54: 11-23. https://doi.org/10.1093/jxb/erg042

Silva ENS, Neto MF, Pereira TNS and Pereira MG (2012). Meiotic behavior of wild Caricaceae species potentially suitable for papaya improvement. Crop Breed. Appl. Biotechnol. 12: 52-59. https://doi.org/10.1590/S1984$\underline{70332012000100007}$

Silva GS and Souza MM (2013). Genomic in situ hybridization in plants. Genet. Mol. Res. 12: 2953-2965. https://doi. org/10.4238/2013.August.12.11

Singh RJ (2003). Plant cytogenetics. 2nd edn. CRC Press LLC, Boca Raton.

Genetics and Molecular Research 16 (3): gmr16039582 
Soares-Scott MD, Meletti LM and Recco-Pimentel S (2003). Meiotic behavior and pollen fertility in sexual and somatic hybrids of Passiflora species. Caryologia 56: 129-138. https://doi.org/10.1080/00087114.2003.10589315

Souza MM, Pereira TNS, Viana AP, Pereira MG, et al. (2003). Meiotic irregularities and pollen viability in Passiflora edmundoi Sacoo (Passifloraceae). Caryologia 56: 161-169. https://doi.org/10.1080/00087114.2003.1010589320

Souza MM, Pereira TNS, Viana AP and Silva LC (2004). Pollen viability and fertility in wild and cultivated Passiflora species (Passifloraceae). Beiträge zur Biologie der Pflanzen 73: 359-376.

Souza MM, Viana AP and Pereira TNS (2010). A putative mutante of a self-compatible yellow passion fruit with the corona color as as phenotypic marker. Bragantia 69: 9-16. https://doi.org/10.1590/S0006-87052010000100003

Sumner AT (2003). Chromosomes: Organization and function. Blackwell Publishing, Oxford.

Techio VH, Davide LC and Pereira AV (2006). Meiosis in elephant grass (Pennisetum purpureum), pearl millet (Pennisetum glaucum) (Poaceae, Poales) and their interspecific hybrids. Genet. Mol. Biol. 29: 353-362. https://doi.org/10.1590/ $\underline{\mathrm{S} 1415-47572006000200025}$

Torres GA, Gong Z, Iovene M, Hirsch CD, et al. (2011). Organization and evolution of subtelomeric satellite repeats in the potato genome. G3 (Bethesda) 1: 85-92. https://doi.org/10.1534/g3.111.000125

Yamamoto A, Kitamura K, Hihara D, Hirose Y, et al. (2008). Spindle checkpoint activation at meiosis I advances anaphase II onset via meiosis-specific APC/C regulation. J. Cell Biol. 182: 277-288. https://doi.org/10.1083/jcb.200802053

Yao XC, Ge XH, Chen JP and Li ZY (2010). Intra- and intergenomic relationships in interspecific hybrids between Brassica (B. rapa, B. napus) and a wild species B. maurorum as revealed by genomic in situ hybridization (GISH). Euphytica 173: 113-120. https://doi.org/10.1007/s10681-010-0131-1

Zamariola L, Tiang CL, De Storme N, Pawlowski W, et al. (2014). Chromosome segregation in plant meiosis. Front. Plant Sci. 5: 279. https://doi.org/10.3389/fpls.2014.00279

Zheng JS, Sun CZ, Zhang SN, Hou XL, et al. (2016). Cytogenetic Diversity of Simple Sequences Repeats in Morphotypes of Brassica rapa ssp. chinensis. Front. Plant Sci. 7: 1049. https://doi.org/10.3389/fpls.2016.01049

Zwierzykowski Z, Zwierzykowska E, Taciak M, Jones N, et al. (2008). Chromosome pairing in allotetraploid hybrids of Festuca pratensis x Lolium perenne revealed by genomic in situ hybridization (GISH). Chromosome Res. 16: 575585. https://doi.org/10.1007/s10577-008-1198-6

Genetics and Molecular Research 16 (3): gmr16039582 